\section{Integrative Medicine \\ International}

\title{
Integrative Reserve and Integrative Medicine
}

\author{
Weidong Pan \\ Department of Neurology, Shuguang Hospital Affiliated to Shanghai University of TCM, \\ Shanghai, China
}

If a person has a bigger face, is he or she less prone to suffer from cognitive disorders than a person with a smaller face? Is this possible? If someone has a higher education and higher income, are they less likely to suffer from cognitive disorders than others. Is this possible, too? The answer to both questions is: yes, it is possible [1,2].

We can observe many cases around us in which a very heavy smoker does not get lung cancer even though he or she may have had chronic lung injury for a long time. On the other hand, someone may only smoke a little or once in a while but may get lung cancer. People of the same family and nationality, in the same environment, eating the same food and even of the same age and with the same habits often have different disease morbidities. What is the reason?

The ability to resist morbidity is termed integrative reserve. For example, two people can have the same degree of Alzheimer's disease pathology, but one can appear much more demented than the other. The idea behind cognitive reserve is that the brain actively attempts to compensate for pathology. Some people are able to compensate better, for example, by using more efficient brain networks or alternate networks, and may be able to function normally despite the pathology. People with more neurons might be able to lose more of them before showing a clinical deficit [3].

Integrative reserve is not resistibility and immunity, it is reserve ability or capacity. Nationality, gender, area, smoking, lifestyle, vascular risk factors, aging, physical activity, weight, income and even education level might be reserve factors of disease morbidities. If something can influence the reserve ability, it can be considered a reserve factor. If our body is infected or injured by pathogenic factors, pathological changes will occur, but sometimes we do not become ill immediately. With the development of pathogenic factors, differences in reserve ability decide whether we will suffer from these diseases or not. Based on many reserve factors, we have different morbidity thresholds, and the buffering capacity is the integrative reserve.

Other systems, not only cognitive disorders, also have a reserve, and our body has many types of reserves. Heart failure reserve has been studied in heart rate variability research; if a subject has a $1 / \mathrm{f}$-type temporal scaling heart rate, he or she has a stronger reserve to delay 
heart failure than others $[4,5]$. Many researchers have found that women have ovarian and breast reserves [6-9], vitamins might increase liver reserve [10,11], mitochondrial reserve and physical exercise could increase respiratory reserve $[12,13]$, and that even the same reserve factor can delay different disease morbidities $[14,15]$.

Integrative reserve consists of 2 types: regulatory reserve and nonregulatory reserve. The most frequent type is regulatory reserve, which is regulated by reserve factors, such as weight, smoking, physical activity, vascular risk factors, frailty, lifestyle, dyslipidemia, educational level, pathoglycemia, and even depression. These factors can be regulated by various treatments, such as integrative therapies [16] including tai chi, mind therapy, diet, statins, antidepressants, traditional herbal medicine or acupuncture, and alternative medicines. Genetics, gender, nationality, aging, cranial capacity and intelligence quotient, among others, are nonregulatory reserve factors, and they are virtually unchangeable after birth. Integrative reserve is not simply the ability to delay morbidity for such diseases, the reserve factors can also be layered. Insufficient physical exercise, genetics and a poor diet might be important reserve factors for diabetes, and we might call these factors initial reserve factors. With the development of diabetes, it will function as a pathological factor for coronary diseases [15, 17], so diabetes will be a second reserve factor according to this analogy.

Ancient traditional Chinese medicine (TCM), which is one type of integrative medicine, has advocated 'prevention before the disease appears' for over 2,000 years, and this concept is very similar to integrative reserve. TCM has already provided many effective therapies to deal with the prevention or delay of disease appearance $[18,19]$.

Integrative medicine plays an important role in regulating reserve factors. It includes any treatment that will, through joint efforts, be able to make greater contributions to boosting medical advances and safeguarding human health [20], which is a means of combining any effective method or treatment from complementary and alternative medicine or traditional and Western medicine, in order to avoid misdiagnoses, side effects or unilateral treatment, improve quality of life, and prolong lives [16].

\section{Acknowledgement}

This study was sponsored by The National Natural Science Foundation of China (81373619).

\section{Disclosure Statement}

The author declares that there are no conflicts of interest regarding the publication of this article.

\section{References}

1 Amieva H, Mokri H, Le Goff M, Meillon C, Jacqmin-Gadda H, Foubert-Samier A, Orgogozo JM, Stern Y, Dartigues JF: Compensatory mechanisms in higher-educated subjects with Alzheimer's disease: a study of 20 years of cognitive decline. Brain 2014;137(Pt 4):1167-1175.

-2 O'Shea DM, Fieo RA, Hamilton JL, Zahodne LB, Manly JJ, Stern Y: Examining the association between late-life depressive symptoms, cognitive function, and brain volumes in the context of cognitive reserve. Int J Geriatr Psychiatry 2014, Epub ahead of print

-3 Yoshizawa H, Gazes Y, Stern Y, Miyata Y, Uchiyama S: Characterizing the normative profile of 18F-FDG PET brain imaging: sex difference, aging effect, and cognitive reserve. Psychiatry Res 2014;221:78-85.

4 Struzik ZR, Hayano J, Soma R, Kwak S, Yamamoto Y: Aging of complex heart rate dynamics. IEEE Trans Biomed Eng 2006;53:89-94.

5 Togo F, Kiyono K, Struzik ZR, Yamamoto Y: Unique very low-frequency heart rate variability during deep sleep in humans. IEEE Trans Biomed Eng 2006;53:28-34. 
6 Hamy AS, Porcher R, Cuvier C, Giacchetti S, Schlageter MH, Coussieu C, Gronier H, Feugeas JP, Adoui N, Lacorte JM, et al: Ovarian reserve in breast cancer: assessment with anti-Müllerian hormone. Reprod Biomed Online 2014, Epub ahead of print.

7 Kondapalli LA, Dillon KE, Sammel MD, Ray A, Prewitt M, Ginsberg JP, Gracia CR: Quality of life in female cancer survivors: is it related to ovarian reserve? Qual Life Res 2014;23:585-592.

-8 Gracia CR, Sammel MD, Freeman E, Prewitt M, Carlson C, Ray A, Vance A, Ginsberg JP: Impact of cancer therapies on ovarian reserve. Fertil Steril 2012;97:134-140.e1.

-9 Lutchman Singh K, Muttukrishna S, Stein RC, McGarrigle HH, Patel A, Parikh B, Groome NP, Davies MC, Chatterjee R: Predictors of ovarian reserve in young women with breast cancer. Br J Cancer 2007; 96:1808-1816.

10 Souza G, Dolinsky M, Matos A, Chagas C, Ramalho A: Vitamin A concentration in human milk and its relationship with liver reserve formation and compliance with the recommended daily intake of vitamin A in pre-term and term infants in exclusive breastfeeding. Arch Gynecol Obstet 2014, Epub ahead of print.

11 Nanashima A, Abo T, Arai J, Matsumoto H, Kudo T, Nagayasu T: Functional liver reserve parameters predictive for posthepatectomy complications. J Surg Res 2013;185:127-135.

12 Desler C, Hansen TL, Frederiksen JB, Marcker ML, Singh KK, Juel Rasmussen L: Is there a link between mitochondrial reserve respiratory capacity and aging? J Aging Res 2012;2012:192503.

13 Gosselin LE, Megirian D, Rodman J, Mueller D, Farkas GA: Respiratory muscle reserve in rats during heavy exercise. J Appl Physiol 1997;83:1405-1409.

14 Jones LW, Haykowsky M, Pituskin EN, Jendzjowsky NG, Tomczak CR, Haennel RG, Mackey JR: Cardiovascular reserve and risk profile of postmenopausal women after chemoendocrine therapy for hormone receptorpositive operable breast cancer. Oncologist 2007;12:1156-1164.

15 Atar AI, Altuner TK, Bozbas H, Korkmaz ME: Coronary flow reserve in patients with diabetes mellitus and prediabetes. Echocardiography 2012;29:634-640.

16 Pan W, Zou H: Inclusion of integrative medicine in clinical practice. Integr Med Int 2014;1:1-4.

17 Nemes A, Forster T, Geleijnse ML, Kutyifa V, Neu K, Soliman OI, Ten Cate FJ, Csanady M: The additional prognostic power of diabetes mellitus on coronary flow reserve in patients with suspected coronary artery disease. Diabetes Res Clin Pract 2007;78:126-131.

18 Shen J, Ma H, Xu H, Wang Y, Lu B, Tang L: Research review and prospect of TCM 'preventive treatment of disease'. Shen Zhen Guo Yi Guo Yao 2014;25:1468-1470.

19 Chen P: Advantages of 'treating latent disease before onset' therapy for subhealth. Shang Hai Zhong Yi Yao Za Zhi 2008;42:60-61.

20 Pan W, Zhou H: Integrative medicine: a paradigm shift in clinical practice. Int J Integr Med 2013;1:21. 